\title{
Yavru Koi Sazan (Cyprinus carpio) Diyetlerine Katılan Keçiboynuzu (Ceratonia siliqua) Tohumunun Besleme Değeri*
}

\author{
Merve ÖNCÜLOKUR**, Mehmet ORUÇ, Hakan Murat BÜYÜKÇAPAR \\ KSÜ, Ziraat Fakültesi, Su Ürünleri Bölümü, Kahramanmaraş
}

\author{
Geliş Tarihi (Received) : 19.11.2014
}

Kabul Tarihi (Accepted) : 05.01.2015

\begin{abstract}
Özet: Çalışmada rasyonlara farklı oranlarda keçiboynuzu tohumu ilave edilerek koi sazanı (Cyprinus carpio) balıklarının 60 günlük deneme boyunca büyüme parametreleri, yem dönüşüm oranı, canlı ağırlık artışı, kondisyon faktörü üzerine etkileri araştırılmıştır. Keçiboynuzu (Ceratonia siliqua) tohumu diyetlere \%0, 10, 20, 30, 40 oranlarında katılmıştır $\left(\mathrm{K}_{0}, \mathrm{~K}_{1}, \mathrm{~K}_{2}, \mathrm{~K}_{3}, \mathrm{~K}_{4}\right)$. Denemede büyüme parametreleri bakımından $\mathrm{K}_{1}$ ve $\mathrm{K}_{2}$ diyet grupları ile $\mathrm{K}_{0}$ grubu arasında fark saptanmazken ( $\left.\mathrm{P}>0.05\right)$, yüksek oranda (\%20 den fazla) keçiboynuzu tohumu katılan $\mathrm{K}_{3}$ ve $\mathrm{K}_{4}$ diyet grupları $\mathrm{K}_{0}$ grubuna göre düşük bulunmuştur $(\mathrm{P}<0.05)$. Sonuç olarak keçiboynuzu tohumu koi sazan yemlerinde alternatif yem katkı maddesi potansiyeline sahiptir ve herhangi bir olumsuz etkisi olmaksızın rasyonlara $\% 20$ ’ye kadar katılabilir.
\end{abstract}

Anahtar kelimeler: Keçiboynuzu, Koi sazanı, Cyprinus carpio, Büyüme, Balık unu

\section{Nutritive Value of Carob Kernel Flour (Ceratonia siliqua) Seed as Ingredient in Diet for Koi Carp (Cyprinus carpio) Fingerlings}

\begin{abstract}
In the study different proportions of carob seeds by adding in diets. Koi carp (Cyprinus carpio) fish 60day trial for growth parameters, feed conversion of ratio, live weight gain, condition factor upon were investigated. Carob kernel flour (Ceratonia siliqua) seeds to diets containing 0\%, 10, 20, 30, 40 participated $\left(\mathrm{K}_{0}, \mathrm{~K}_{1}, \mathrm{~K}_{2}, \mathrm{~K}_{3}, \mathrm{~K}_{4}\right)$ respectively. There were no significant differences $(\mathrm{P}>0.05)$ among fish fed diets $\mathrm{K}_{0}, \mathrm{~K}_{1}$ and $\mathrm{K}_{2}$ in terms of growth parameters. Fish fed diets containing higher levels (>20\%) $\mathrm{K}_{3}$ and $\mathrm{K}_{4}$ had significantly lower than $\mathrm{K}_{0}$ diets. Results show that carob kernel flour seed has potential as an alternative feed ingredient in diets for fingerling koi carp (Cyprinus carpio) with no adverse effect. Carob kernel flour seed can be used up to $20 \%$.
\end{abstract}

Key Words: Carob kernel flour, koi carp, Cyprinus carpio, the growth, fishmeal

\section{GíRiș}

Yem rasyonlarında balıklar için en ideal protein kaynağı olan balık unu, miktarındaki yetersizlik ve yüksek fiyatından dolayı günümüzde yem ham maddesi olarak kullanımında sıkıntılar yaşanmaktadır. Özellikle büyük ölçekte üretimi yapılan türlerin yemlerinde balık ununa alternatif, kolay temin edilen daha ucuz ham maddelere yer verilmesi bir zorunluluk haline gelmiştir (Chong,2003).

Günümüzde balık yemi formülasyonlarında yaygın olarak kullanılan bitkisel protein kaynaklarından başka yöresel olarak değerlendirilebilecek bazı protein kaynakları da mevcuttur. Bunlar, bezelye (Overland ve ark., 2009), kırmızı mercimek (Ustaoğlu ve ark., 2009), koca fiğ (Vicia narbonensis) (Büyükçapar ve ark., 2010), misir gluteni (Regost ve ark., 1999), culban (Vicia peregrina) (Büyükçapar ve Kamalak, 2006; Büyükçapar, 2012), yabani bezelye (Pisum elatius) (Büyükçapar ve Kamalak, 2010)'dir.

$\mathrm{Bu}$ çalışmada yerel bitkisel protein kaynağı olarak doğadan toplanarak kurutulan ve un haline getirilen keçiboynuzu (Ceratonia siliqua) tohumunu, hazırladığımız yem rasyonlarına balık unu, misır unu ve soya unu ile birlikte $\% 0,10,20,30,40$ oranlarında katılarak yem diyetleri hazırlanmıştır. $\mathrm{Bu}$ hazırlanan diyetlerle koi sazan (Cyprinus carpio) yavruları beslenerek, büyüme parametreleri üzerine etkisi araştırılmıştır.

\section{MATERYAL ve METOT}

\section{Diyet hazırlama}

Keçiboynuzu (Ceratonia siliqua) tohumu Mersin İlinin Tarsus İlçesindeki özel bir işletmeden temin edilmiştir. Temin edilen tohumlar ögütülerek un haline getirilmiştir. Diyetlere keçiboynuzu tohumu ham olarak $(\% 0,10,20,30,40)$ katılmıştır. Keçiboynuzu tohumu, balık unu, soya küspesi ve misır ununun kimyasal kompozisyonları Çizelge 1'de, deneme rasyonları ise Çizelge 2'de verilmiştir. Keçiboynuzunun aminoasit ve yağ asit içerikleri Çizelge 3'deki gibidir.

Denemede kullanılan rasyonların enerji ve protein oranları dengelenmiştir. Rasyonları oluşturan bütün birleșenler mikserde karıştırıldıktan sonra \%30 su katılarak hamur haline getirilmiştir. Daha sonra et makinesinin 2 no'lu eleğinden geçirilerek pelet haline getirilen diyetler $55^{\circ} \mathrm{C}$ 'de 12 saat etüvde kurutulmuştur. Kontrol diyetinde ana protein kaynağ 1 olarak \%30 oranında balık unu ve $\% 25$ oranında soya küspesi kullanılmıştır.

\footnotetext{
* Bu çalışma KSÜ BAP tarafından desteklenen 2013/6-11 nolu yüksek lisans projesinden elde edilmiştir

** Sorumlu yazar: Öncülokur, M., mrv_okur@hotmail.com
} 
Çizelge 1. Karma yemlere katılan keçiboynuzu (Ceratonia siliqua), balık unu, mısır unu ve soya ununun kuru maddedeki kimyasal kompozisyonu

\begin{tabular}{lllll}
\hline Besin birleşenleri $(\mathrm{g} / \mathrm{kg})$ & Balık unu & Soya unu & Misır unu & Keçiboynuzu \\
\hline Ham Protein & 701.6 & 470.0 & 78.0 & 155 \\
Ham Yağ & 110 & 10 & 35.2 & 25 \\
Ham Kül & 135.0 & 60.0 & 55.2 & 50 \\
Ham Selüloz & 5.0 & 60.0 & 26.0 & 78 \\
Kuru Madde & 900.6 & 890.0 & 881.3 & 930 \\
Toplam enerji $(\mathrm{MJ} / \mathrm{kg})^{*}$ & 21.3 & 17.5 & 16.21 & 11.59 \\
\hline
\end{tabular}

*Hesaplanmış değer; toplam enerji balık unu için $23.6 \mathrm{kj} / \mathrm{g}$, ham yağ için $39.5 \mathrm{kj} / \mathrm{g}$ ve karbonhidrat için ise $17.2 \mathrm{kj} / \mathrm{g}$ değerlerinden yararlanarak hesaplanmıştır(NRC,1993).

Cizelge 2. Deneme rasyonlarının formülasyonu ve besin bileșenleri

\begin{tabular}{|c|c|c|c|c|c|}
\hline \multirow{2}{*}{$\begin{array}{l}\text { Diyet } \\
\text { Birleşenleri (g/kg) }\end{array}$} & $\mathrm{K}_{0}$ & $\mathrm{~K}_{1}$ & $\mathrm{~K}_{2}$ & $\mathrm{~K}_{3}$ & $\mathrm{~K}_{4}$ \\
\hline & $\% 0$ & $\% 10$ & $\% 20$ & $\% 30$ & $\% 40$ \\
\hline Balık unu & 300 & 280 & 260 & 240 & 220 \\
\hline Soya unu & 250 & 250 & 250 & 250 & 250 \\
\hline Keçiboynuzu & 0 & 100 & 200 & 300 & 400 \\
\hline Misir unu & 361 & 277 & 193 & 105 & 21 \\
\hline Ayçiçek yağ1 & 74 & 78 & 82 & 90 & 94 \\
\hline $\mathrm{DCP}^{1}$ & 1 & 1 & 1 & 1 & 1 \\
\hline Vit-Min ${ }^{2}$ & 5 & 5 & 5 & 5 & 5 \\
\hline Mermer tozu & 1 & 1 & 1 & 1 & 1 \\
\hline Tuz & 1 & 1 & 1 & 1 & 1 \\
\hline Methionine & 1 & 1 & 1 & 1 & 1 \\
\hline Lysine & 1 & 1 & 1 & 1 & 1 \\
\hline Toplam & 1000 & 1000 & 1000 & 1000 & 1000 \\
\hline \multicolumn{6}{|l|}{ Besin bileşenleri $(\mathrm{g} / \mathrm{kg})$} \\
\hline Ham protein & 356 & 351 & 346 & 344 & 342 \\
\hline Ham yağ & 122.13 & 123.49 & 124.85 & 130.07 & 131.43 \\
\hline Ham selüloz & 45.38 & 46.36 & 47.34 & 48 & 48.98 \\
\hline Ham kül & 75.42 & 73.09 & 70.73 & 68.196 & 65.85 \\
\hline Kuru madde & 810.82 & 811.78 & 812.74 & 810.18 & 811.12 \\
\hline Toplam Enerji $(\mathrm{MJ} / \mathrm{kg})^{3}$ & 19.507 & 19.041 & 18.575 & 18.663 & 18.137 \\
\hline
\end{tabular}

${ }^{1}$ Di calsiyum Fosfat

${ }^{2}$ Her 5kg'da bulunan vitamin mineral içerikleri 200.000.000 IU vitamin A, 200.000 IU vitamin D3, $200.000 \mathrm{mg}$ vitamin E, 12,000 mg vitamin $\mathrm{K}_{3}, 20.000 \mathrm{mg}$ vitamin $\mathrm{B} 1,30.000 \mathrm{mg}$ vitamin $\mathrm{B} 2,200.000 \mathrm{mg}$ niasin, $50.000 \mathrm{mg}$ Capanthothenate, $20.000 \mathrm{mg} \mathrm{B} 6,50 \mathrm{mg}$ vitamin B12, $50 \mathrm{mg}$ vitamin B12, $500 \mathrm{mg}$ D-biytin, 1,200 mg folik asit, $200.000 \mathrm{mg}$ vitamin $\mathrm{C}$ ve $300.000 \mathrm{mg}$ inositol, $1.200 .000 \mathrm{mg}$ cholin klorit, $40.000 \mathrm{mg}$ manganez, $30.000 \mathrm{mg}$ çinko, $800 \mathrm{mg}$ bakır, $1.000 \mathrm{mg}$ iyodin, $150 \mathrm{mg}$ selenyum, $40.000 \mathrm{mg}$ magnesyum bulunmaktadır.

${ }^{3}$ Hesaplanmış değer; toplam enerji balık unu için $23.6 \mathrm{kj} / \mathrm{g}$, ham yağ için $39.5 \mathrm{kj} / \mathrm{g}$ ve karbonhidrat için ise $17.2 \mathrm{kj} / \mathrm{g}$ değerlerinden yararlanarak hesaplanmıştır (NRC,1993).

Balık ve akvaryum sistemleri

Araştırmada kullanılacak koi sazanı yavruları özel sektöre ait işletmeden (Adana) KSÜ Ziraat Fakültesi Su Ürünleri Bölümü'ne transfer edilmiştir. İşletmeden getirilen koi sazan yavruları öncelikle \%10'luk metilen mavisinde parazitten arındırılmıştır. Getirilen balıklar ortalama 4 g'dan 12 g olana kadar 250 lt'lik fiberglas tanklarda tutulmuştur. Deneme başlangıcından 7 gün önce balıklar tanklardan alınmış boy ve ağırlık ölçümleri yapılarak 80lt'lik akvaryumlara yerleştirilmiştir. Deneme 2 yinelemeli 5 diyet grubundan oluşmuştur. Balıklar 15 gün boyunca kontrol diyetiyle beslenmiş ve adaptasyonları sağlanmıştır. Bu süre içinde hasta ve ölen balıklar akvaryumdan uzaklaştırılmıştır. Deneme 60 gün süresi olup balıklar vücut ağırlıklarının \%3'ü oranında doyuncaya kadar beslenmiştir. Deneme başlangıcındaki ağırlıkları yaklaşık $12 \mathrm{~g}$ olan balıklardan her akvaryuma 10 adet yerleştirilmiştir ve 20 günde bir tartım yapılarak vücut ağırlığına göre verilen yem miktarı artırılmıştır. Akvaryumlarda havalandırma hava motoru ile merkezi olarak sağlanmış, hava hortumu ile eşit dağıtılmıştır. Balıkların konulduğu akvaryumlardaki suyun \%50'si ve filtreler 10 günde bir değiştirilip temizlenmiştir. Akvaryumlarda su kalitesi iç ve diş filtrelerle kontrol altında tutulmuş olup sıcaklık ve oksijen oranları günlük ölçülüp, pH oranları ise haftalık olarak ölçülmüştür. 
Çizelge 3. Keçiboynuzu aminoasit, yağ asit içerikleri

\begin{tabular}{llll}
\hline Esansiyel aminoasitler & $(\mathrm{g} / \mathrm{kg})$ & Esansiyel Yă̆ asitleri & $\%$ \\
\hline Fenilalanin & 4.43 & Arachidonic asit & 0.314 \\
Histidin & 2.94 & Palmiteolic asit & 1.052 \\
İzolöysin & 4.38 & Oleic asit & 35.816 \\
Löysin & 7.62 & Linoleik asit & 36.49 \\
Metiyonin & 1.18 & Linolenic asit & 0.84 \\
Treonin & 0.74 & Cis-11-Eicosenoic asit & 0.045 \\
Lizin & 11.43 & Cis-11,14-Eicosatrienoic asit & 0.037 \\
Arjinin & 10.3 & Cis-5.8.11.14.17-Eicosapentaenoic asit & 0.191 \\
Triptofan & 1.13 & Nervonic asit & 0.15 \\
Valin & 5.49 & & $\%$ \\
\hline Esansiyel Olmayan Aminoasitler & $(\mathrm{g} / \mathrm{kg})$ & Esansiyel Olmayan Yağ Asitleri & 0.156 \\
\hline Alanin & 4.97 & Myristic asit & 0.07 \\
Aspartik asit & 11.06 & Pentadecanoic asit & 0.07 \\
Prolin & 5.17 & Cis-10-Heptadecanoic asit & 0.038 \\
Glutamik asit & 36.52 & Tricosanoic asit & 15.61 \\
Serin & 4.39 & Palmitic asit & 0.119 \\
Glisin & 6.14 & Heptadecanoic asit & 4.512 \\
Tirozin & 3.5 & Stearic asit & 0.129 \\
& & Arachidonic asit & 0.398 \\
& & Behenic asit & 0.077 \\
& & Heneicosanoic asit & 0.533 \\
\hline
\end{tabular}

\section{Yemleme zamanı}

Balıklar günlük 9:00 ve 17:00 saatleri arasında vücut ağırlıklarının \%3’ü kadar beslenmiştir.

\section{Kimyasal Analizler}

Keçiboynuzu tohumu ve diğer besin maddelerinin kimyasal kompozisyonları AOAC (1990)'a göre yapılmıştır. Keçiboynuzu tohumunun aminoasit ve yağ asit analizleri TUBİTAK MAM tarafından yapılmıştır.

\section{Hesaplamalar}

Deneme bitimi sonucunda elde edilen büyüme parametreleri ve yem dönüşüm oranlarına ilişkin değerlerin hesaplamasında kullanılan formüller aşağıda verilmiştir.

Canlı ăgırlık artışı $(g)=$ Deneme sonu canlı ăgırlık $(g)$ Deneme başlangıcı canlı ăgrılık (g)

SGR (Spesifik Büyüme Oranı) = ln periyot sonu ağırlık (g) - In periyot başı ăgırlık (g) / yemlenen gün sayısı) X 100

YDO (Yem Dönüşüm Oranı) = Tüketilen yem miktarı $(g)$

- Canlı ağırlık artışı (g)

PER (Protein etkinlik oranı) $=$ Canlı ağırlık artışı $(g)-$ Yemle alinan protein

Kondisyon Faktörü $=\left[\right.$ A $\breve{g l r l}$ lk $\left.(g) /(\text { Total boy })^{3}(\mathrm{~cm})\right] \mathrm{X}$ 100
Denemeye ait araştırma verileri,"Varyans analizi" ve "Duncan çoklu karıştırma testi"nde 0,05 önem düzeyine göre değerlendirilmiş olup söz konusu istatistiksel analizler SPSS paket programında yapılmıştır.

\section{BULGULAR ve TARTISMA}

Deneme boyunca ölçülen oksijen (mg/It), sıcaklık $\left({ }^{\circ} \mathrm{C}\right)$ ve $\mathrm{pH}$ değerleri ortalama değerleri verilmiş olup, sirasiyla oksijen $6.4 \pm 0.02-6.8 \pm 0.09 \mathrm{mg} / \mathrm{It}$, sicaklık $27.5 \pm 0.02-29.4 \pm 0.08{ }^{\circ} \mathrm{C}$ ve $\mathrm{pH} \quad 8.36 \pm 0.02$ $8.47 \pm 0.08$ arasında değişmiştir.

Deneme süresince balıklarda yem almama ve yemden kaynaklanan herhangi bir ölüm olay1 gözlenmemiştir. Çalışmada elde edilen, deneme sonu itibariyle ortalama canlı ağırlı kazancı, yem değerlendirme oran1, protein etkinlik oran1, spesifik büyüme oran1, kondisyon faktörü Çizelge 4'de gösterilmiştir.

Başlangıçta ortalama $12 \mathrm{~g}$ civarı olan balıklar ( $\mathrm{P}>0.05)$, deneme sonunda $30.41 \mathrm{~g}$ ile $26.71 \mathrm{~g}$ arasinda değişmiştir $(\mathrm{P}<0.05)$. Deneme sonu itibariyle $\mathrm{K}_{0}$ grubuyla $K_{1}$ ve $K_{2}$ diyet grupları arasında fark görülmezken, $\mathrm{K}_{3}$ ve $\mathrm{K}_{4}$ grupları diğer gruplara göre düşük çıkmıştır (Çizelge 4). Diğer büyüme parametreleri de yaklaşı olarak büyüme performansına benzer şekilde saptanmıştır (Çizelge 4). 
Çizelge 4. Deneme sonu itibariyle canlı ağırlık kazancı, spesifik büyüme oranı ve yem değerlendirme oranı, protein etkinlik oranı, kondisyon faktörü

\begin{tabular}{llllll}
\hline & $\mathrm{K}_{0} \% 0$ & $\mathrm{~K}_{1} \% 10$ & $\mathrm{~K}_{2} \% 20$ & $\mathrm{~K}_{3} \% 30$ & $\mathrm{~K}_{4} \% 40$ \\
\hline Başlangıç ağrılığı $(\mathrm{g})$ & $12.56 \pm 0.8^{\mathrm{a}}$ & $12.71 \pm 0.8^{\mathrm{a}}$ & $12.93 \pm 0.8^{\mathrm{a}}$ & $12.83 \pm 1.9^{\mathrm{a}}$ & $12.61 \pm 0.8^{\mathrm{a}}$ \\
Final ağırlığı $(\mathrm{g})$ & $30.41 \pm 1.6^{\mathrm{a}}$ & $28.85 \pm 1.4^{\mathrm{ab}}$ & $28.47 \pm 1.4^{\mathrm{ab}}$ & $26.9 \pm 1.5^{\mathrm{b}}$ & $26.71 \pm 1.1^{\mathrm{b}}$ \\
Ağırlık kazancı $(\mathrm{g})$ & $17.85 \pm 1.2^{\mathrm{a}}$ & $16.13 \pm 1.1^{\mathrm{ab}}$ & $15.54 \pm 1.1^{\mathrm{ab}}$ & $14.07 \pm 1.3^{\mathrm{b}}$ & $14.1 \pm 1.03^{\mathrm{b}}$ \\
Yem alımı (g) & $27.7 \pm 1.2^{\mathrm{a}}$ & $28.3 \pm 1.2^{\mathrm{a}}$ & $27.8 \pm 1.3^{\mathrm{a}}$ & $27.4 \pm 1.5^{\mathrm{b}}$ & $27.4 \pm 1.5^{\mathrm{b}}$ \\
YDO & $1.55 \pm 0.1^{\mathrm{a}}$ & $1.76 \pm 0.2^{\mathrm{a}}$ & $1.79 \pm 0.2^{\mathrm{ab}}$ & $1.95 \pm 0.1^{\mathrm{b}}$ & $1.95 \pm 0.1^{\mathrm{b}}$ \\
PER (\%) & $1.624 \pm 0.2^{\mathrm{a}}$ & $1.507 \pm 0.1^{\mathrm{a}}$ & $1.459 \pm 0.1^{\mathrm{a}}$ & $1.372 \pm 0.1^{\mathrm{a}}$ & $1.417 \pm 0.1^{\mathrm{a}}$ \\
SGR (\%) & $1.473 \pm 0.1^{\mathrm{a}}$ & $1.366 \pm 0.1^{\mathrm{a}}$ & $1.314 \pm 0.1^{\mathrm{ab}}$ & $1.232 \pm 0.09^{\mathrm{ab}}$ & $1.25 \pm 0.08^{\mathrm{b}}$ \\
Kondisyon Faktörü (\%) & $1.653 \pm 0.05^{\mathrm{a}}$ & $1.717 \pm 0.05^{\mathrm{a}}$ & $1.743 \pm 0.03^{\mathrm{a}}$ & $1.816 \pm 0.04^{\mathrm{ab}}$ & $1.734 \pm 0.09^{\mathrm{ab}}$ \\
\hline
\end{tabular}

*Her satırda aynı harfle gösterilen ortalamalar istatiksel olarak benzerdir $(\mathrm{P}>0.05)$

Rasyona katılan keçiboynuzu tohumunun \%20'den fazla eklenmesi balıklardaki büyüme parametrelerini olumsuz şekilde etkilemiştir. Bu Borlongan ve ark (2003) tarafından da rapor edildiği gibi proteinin etkin bir şekilde kullanılmamasına bağlı olarak besin ve enerji kullanımındaki azalmadan kaynaklanmış olabilir. Bitkisel protein kaynakları birçok anti besinsel faktörler içerirler. $\mathrm{Bu}$ anti besinsel faktörler bitkisel proteinlerin, balık unu ve diğer proteinlerin yerine balık diyetlerinde kullanılmasını sınırlandırır (Tacon, 1997). Diyetlere yüksek oranda bitkisel kökenli protein kaynağının katılması, bu faktörlerin devreye girerek diyetlerde bulunan proteinin emilimini engellemektedir (Adebayo ve ark. 2004). Bu faktörlerin balık gelişimi üzerine etkileri ile ilgili olarak Olvera ve ark.,(1998) baklagillerde anti besinsel faktörler düşük seviyelerde de olsa balık gelişimini etkileyebileceğini söylemişlerdir. Tohumlarda bulunan bu faktörlerin elemine edilebilmesi için kullanılan yöntemlerden biri de tohumun ya 1sitılması ya da otoklavda bekletilmesidir (Grant 1991). Benzer şekilde sazan diyetlerine culban (Vicia peregrina) ham şekilde en fazla \% 10 oranında katılabileceği saptanırken bu oran 1sıtılmış culban için \%20 olarak rapor edilmiştir (Büyükçapar ve Kamalak, 2006). Yapılan diğer bir araştırmada ise aynalı sazan yavrularının diyetlerine ham ve 1sıtılmış olarak yabani bezelye (Pisum elatius)'nin katıldığı çalışmada, bezelye diyetlere en fazla \%10 ham olarak katılabilirken 1sıtıldığında bu oran \%30'a kadar çıktığı rapor edilmiştir (Büyükçapar ve Kamalak, 2010). Bu çalışmada koi sazan (Cyprinus carpio) yemlerine keçiboynuzu (Ceratonia siliqua) tohumunun ham olarak \%20 seviyesine kadar ilave edilmesi mümkün olduğu görülmüştür. $\mathrm{Bu}$ oranın artması için keçiboynuzu tohumunun 1sıtılması bir yöntem olarak düşünülebilir. Ancak şu unutulmamalı ki 1sıl işleme maruz bırakılmış baklagillerin sindirilebilir enerjileri düşmektedir. Buda 1sıtma işleminin rasyonlara katılacak bitkisel protein kaynaklarının oranlarını çok fazla arttırılmasına olanak vermemektedir. Özellikle de bu durum alabalık rasyonlarında 1 sıtılmış bitkisel protein kaynaklarının kullanılmasını sınırlamaktadır (Pfeffer ve ark., 1995).

\section{SONUÇ}

Bu çalışmada koi sazan (Cyprinus carpio) yemlerine keçiboynuzu (Ceratonia siliqua) tohumunun \%20 seviyesine kadar ilave edilmesinin mümkün olduğu görülmüştür. Koi sazan (Cyprinus carpio) yemlerine yüksek oranlarda keçiboynuzu (Ceratonia siliqua) tohumu ilavesi yem tüketimi, büyüme, yem değerlendirme, protein etkinlik oranı gibi değerlerin düşmesine yol açmıştır. Balık ununun sınırlı miktarlarına karşılık, kolay ve ucuz temin edilen bitkisel protein kaynaklarının kullanım olanaklarının araştırılması gerekmektedir.

\section{KAYNAKLAR}

Adebayo, O.T., Fagbenro, O.A., Jedege, T. 2004. Evaluation of Cassia fisculata Meal As A Replacement for Soybean Meal in Practical Diets of Oreochromis niloticus Fingerlings. Aquaculture Nutr., 10: 99-104.

AOAC, 1990. Oficial methods of analysis (15th ed.) Association of official analytical chemisits, Washington DC, USA. Pp.69-88.

Borlongan, I. G., Eusebio, P. S., Welsh, T. 2003. Potential of feed pea (Pisum sativum) meal as a protein source in practical diets for milkfish (Chanos chanos Forsskal). Aquaculture, 225: (1-4), 89-98.

Büyükçapar, H.M., Kamalak, A. 2006. Raw and Heat treated Culban (Vicia peregrine) seed as Protein source for Mirror carp (Cyprinus carpio) fingerlings. South Afr. Journ. of Animal Science, 36(4):235-242.

Büyükçapar, H.M., Mezdegi, İ., Kamalak, A. 2010. Nutritive Value of Narbon Bean (Vicia narbonensis) Seed as Ingredients in Practical Diet for Tilapia (Oreochromis niloticus) Fingerlings. J. Appl. Anim. Res., 37:253-256.

Büyükçapar, H.M., Kamalak, A. 2010. Nutritive value of wild pea (Pisum elatius) seeds as dietary protein source for mirror carp, (Cyprinus carpio), fingerlings. Israeli Journal of Aquaculture Bamidgeh, 62(4), 272-280.

Büyükçapar, H.M. 2012. Growth performance and body composition in mirror carp (Cyprinus carpio) fed culban seed (Vicia peregrina) with different heat treatments. Kafkas Üniversitesi Veteriner Fakültesi Dergisi, 18 (3): 389-394. 
Chong, A. 2003. Assesment of soybean meal in diets for Discus (Symphysodon aequifasciata HECKEL) farming through a fish meal replacement study. Aquaculture Research, 34: 913-922.

Grant, G. 1991. Toxic Substances in Crop Plants. The Royal Society of Chemistry, Thomas Graham House, Science Park, Cambridge Cb4 4wff, Cambridge, Pp. 49-67.

NRC 1993. Nutrient Requirements Of Fish, National Research Council, 114 Pp. The National Academies Press, Washington.

Oliviera N.M.A., Martinez, P., Galvan, C.R. 1998. The use of seed of the leguminous plant (Sesbania graniflora) as a partial replacement of this meal diets for tilapia (Oreochromis massambicus). Aquaculture 71:51-60.

Overland, M., Storebakken, T., Penn, M., Kroghdel, A., Skrede, A. 2009. Pea concentrate substituting fish meal or soybean meal in diets for Atlantic Salmon (Salmo salar)-Effect on growth performance, nutrient digestibility, carcass composition, gut health and physical feed quality. Aquaculture, 288: 305311.

Pfeffer, E., Kizginger, S., Rodelhutscord, M. 1995. Influence of the proportion of poultry slaughter byproducts and of untreated or hydrothermically treated legume seeds inn diets for rainbow trout, (Oncorhynchus mykiss), (Walbaum), on apparent digestililities of their energy and organic compounds. Aquaculture Nutr., 1:111-117.

Regost, C., Arzel, J., Kaushik, S.J. 1999. Partial or total replacement of fish meal by corn gluten meal in diet for turbot (Psetta maxima). Aquaculture, 180: 99117.

Tacon, A.G.J. 1997. Fish Meal Replacers: Review of Antinutrients Within Oilseed and Pulses. A Limiting Factor for the Aqua Feed Green Revolution? In: Feeding tommorrow's Fish. Eds. Tacon, A.G.J. and Basurco, B., Pp. 153-182. Cahiers Options Mediterraneennes. Instut Agronomique Mediterraneenne de Zaragoza, Spain.

Ustaoğlu, S., Karayücel, İ., Alagil, F., Dernekbaşı, S., Yağc1, F. 2009. Evaluation of extruded chickpea, common bean and red lentil meals as protein source in diets for juvenile Rainbow trout (Oncorhynchus mykiss). Journal of Animal and Veterinary Advances, 8 (10): 2079-2086. 